\title{
SOBRE OS MÉTODOS HISTÓRICOS
}

\author{
Regarding historical method \\ Antônio César de Almeida Santos*
}

\begin{abstract}
SKINNER, Quentin. Visões da politica: sobre os métodos históricos. Algés: Difel, 2005. 293 p. Tradução de João Pedro George - original publicado pela Cambridge University Press, em 2002.
\end{abstract}

Quentin Skinner ora identifica-se como historiador da filosofia, ora como historiador do pensamento, ora como historiador das ideias. Apesar dessa variedade de classificações, seus trabalhos, sem dúvida, circunscrevem-se no que se pode designar, em sentido amplo, como história das ideias políticas, especialmente ao considerarmos obras suas publicadas no Brasil: Maquiavel (Brasiliense, 1988), As fundações do pensamento político moderno (Companhia das Letras, 1996), Razão e retórica na filosofia de Hobbes (Editora da Unesp, 1999), Liberdade antes do liberalismo (Editora da Unesp, 1999) e Hobbes e a teoria clássica do riso (Editora da Unisinos, 2003). Entretanto, nestes trabalhos, são poucas as páginas em que Skinner apresenta considerações acerca de seus pressupostos teóricos e de sua metodologia. No prefácio de As fundações do pensamento político moderno, por exemplo, informa que havia apresentado seus procedimentos de análise num conjunto de artigos, publicados "nos últimos doze anos, e não me parece adequado repetir aqui o que neles argumentei" (1996, p. 10). Em Liberdade antes do liberalismo, ele apresenta alguns aspectos de seu método, o qual, ressalta, era contrastante "com a ortodoxia prevalecente" no campo da história das ideias na década de 1960, afirmando que "os historiadores do pensamento fariam bem em se concentrar não meramente, ou mesmo principalmente, num cânone de assim chamados textos clássicos, mas, preferivelmente, no lugar ocupado por esses textos em tradições e quadros mais amplos do pensamento" $(1999$, p. 83).

* DEHIS/UFPR. 
Não obstante essa disposição em apresentar o seu método enquanto o pratica (ou melhor, enquanto expõe os resultados de sua prática), muitas confusões e incompreensões ainda marcam a recepção de sua abordagem entre nós. Conforme Jasmin e Feres Júnior (2006, p. 11), a abordagem de Skinner foi, "recentemente", rebatizada por ele como "enfoque collingwoodiano". A propósito, como aponta Marcos Antônio Lopes - e concordamos nisso -, a proposta metodológica do historiador britânico contém "elementos disseminados na historiografia contemporânea, pelo menos desde os anos 1920 " (2002, p. 16). Então, o que é que tornou sedutora sua metodologia, nestas últimas décadas? Para Lopes, além das considerações acerca da "relação texto/contexto" e das noções de "intencionalidade autoral", "atos do discurso" e "vocabulário normativo de uma época", foi a sua definição de contexto histórico que acentuou uma contribuição inovadora para "as mais recentes tendências da história intelectual" (idem). Contudo, pouco, ou quase nada, tem adiantado indicar que para a utilização da metodologia de Skinner é essencial "levar em conta o contexto intelectual em que foram concebidos os principais textos" e que, para a realização de uma pesquisa em história intelectual, é preciso considerar "a natureza e os limites do vocabulário normativo disponível em qualquer época dada"; ou, ainda, que se deve "escrever uma história menos concentrada nos clássicos e mais na história das ideologias, tendo por objetivo construir um quadro geral no qual possam ser situados os textos dos teóricos mais proeminentes da política" (SKINNER, 1996, p. 10-11). Não obstante a veemência de tais afirmações, o sentido delas ainda carece, entre nós, de uma melhor apreensão.

Este breve preâmbulo pareceu-me necessário para podermos avaliar a importância, para o leitor de língua portuguesa, da publicação do livro Visões da política, de Quentin Skinner. Originalmente, "Visions of politics é uma obra em três volumes que, de alguma maneira, cobre e atualiza grande parte da produção do autor. O segundo volume versa sobre a teoria política na Renascença; o terceiro, sobre Thomas Hobbes; e o primeiro, intitulado Regarding method, é uma coletânea dos principais textos do autor sobre método" (JASMIN; FERES Jr., 2006, p. 13). Ou seja, para os interessados em uma maior aproximação aos elementos da metodologia do Regius Professor de História Moderna da Universidade de Cambridge, a editora portuguesa Difel publicou, em 2005, esse primeiro volume, dentro da coleção Memória e Sociedade, coordenada por Diogo Ramada Curto. 
Esse volume, além de uma breve introdução, traz, na forma de capítulos, versões revistas - algumas bastante modificadas - de artigos e capítulos de livros publicados entre os anos de 1969 e 1999. São, incluindo-se a Introdução, dez capítulos que exigem, nas palavras de Diogo Ramada Curto, responsável pela Apresentação, uma leitura "necessariamente morosa", mas que possibilitam "perceber os diferentes campos de referências que, ao longo de mais de trinta anos de actividade, inspiraram ou serviram de quadro para uma série de debates" (p. xii).

$\mathrm{Na}$ Introdução [intitulada Ver as coisas como elas são], Skinner reafirma que "se o que pretendemos é uma história da filosofia feita com um espírito genuinamente histórico, devemos ter como uma de nossas principais tarefas a contextualização intelectual dos textos em estudo de forma a que possamos dar sentido ao que os seus autores estavam a fazer quando os escreviam." E, em seguida, explica que, para alcançar esse objetivo, basta "utilizar as técnicas básicas da investigação histórica de forma a captar os seus conceitos [dos autores], seguir as suas distinções, apreciar as suas crenças e, tanto quanto possível, ver as coisas como elas são" (p. 4 - meus destaques). Nesse sentido, Richard Tuck destaca que, para Skinner, "o objetivo importante a ser estabelecido é a similaridade metodológica entre a história das ideias e a história de outras atividades humanas" (1992, p. 286).

A ideia contida na frase "dar sentido ao que os seus autores estavam a fazer" ganha especial relevância na metodologia adotada por Skinner, especialmente por sua aproximação com proposições de Ludwig Wittgenstein e John Austin. Essa aproximação fica evidenciada nos capítulos 5 [Motivos, intenções e interpretação] e 6 [Interpretação e compreensão dos actos discursivos], nos quais ganha importância a noção de ato ilocutório, neologismo criado por Austin e utilizado para expressar a ideia de que é possível "saber aquilo que os autores estão a fazer, assim como aquilo que eles estão a dizer, isto se o nosso objectivo é compreender os seus textos" (p. 118 - grifo no original). Buscar descobrir o que o autor do texto estudado estava "a fazer" coloca em foco a necessidade de se compreender o que ele procurou fazer com a produção de tal texto. Ou seja, ao se pretender compreender um texto, na ótica de Skinner, deve-se "interpretar não apenas o significado do que foi dito, mas também a intenção que o autor em questão pode ter tido ao dizer aquilo que disse" (p. 113). Esse aspecto - a intenção do autor - é especialmente importante para essa abordagem, na 
medida em que "conhecer as intenções é, [...] de uma forma geral, saber que actos discursivos [o autor] estaria a levar a cabo quando escreveu o texto em questão" (p. 136), ou melhor,

[...] falar das intenções de um autor tanto pode dizer respeito a um plano ou desígnio para criar um certo tipo de obra (a intenção de fazer x) como tratar-se de uma referência, em particular, a uma determinada obra (o acto de fazer $\mathrm{x}$ tem subjacente uma intenção específica). [...] Mais especificamente, parece tratar-se de uma caracterização da obra como personificando um objectivo ou intenção particulares e, nesse sentido, como perseguindo um propósito em particular (p. 138-9).

As intenções diferem dos motivos, à medida que estes tratam de condições que antecedem à realização da obra. Aliás, as intenções, na ótica de Skinner, estariam próximas ao sentido atribuído aos atos ilocutórios, pois "fazer uma afirmação peremptória implicará sempre falar não apenas com um certo significado mas também com aquilo que Austin apelidou de força ilocutória" (p. 139).

Apreender motivos e intenções acaba sendo essencial para a compreensão dos textos do próprio Skinner, na medida em que a maioria deles tem, como ponto de partida, o desejo de redigir uma resposta "aos meus críticos" (reply to my critics), como é o caso de importante artigo seu publicado na coletânea organizada por James Tully, Meaning and context: Quentin Skinner and his critics (1988). Dois capítulos de Visões da política - o 3 [Interpretação, racionalidade e verdade] e o 6 [Interpretação e compreensão dos actos discursivos] - derivam desse artigo, o qual, por sua vez, teria origem em proposições anunciadas em texto publicado em 1969 e que ganharam nova formulação no capítulo 4 [Significação e compreensão na história das ideias] do livro em foco. Nesse capítulo 4, ao mesmo tempo em que Skinner faz um veemente e consistente ataque aos modelos de pesquisa então vigentes em história das ideias, declara a sua posição sobre como e o que se deve pesquisar em história das ideias: "A única história das ideias que deve ser feita é a história dos usos a que as ideias estão sujeitas" (p. 119). Essa orientação é retomada e desenvolvida em vários outros capítulos do livro, na medida em que, mais e mais, percebe-se a necessidade de se "compreender a razão que levou um autor a apresentar uma certa proposição, isto se quisermos compreender essa mesma proposição" (p. 162). 
Assim, contrariamente à sua anunciada morte, o autor é outro elemento crucial para a interpretação das obras a que nos propusermos a estudar. Com isso, a noção de "ação social" ganha relevância e, ao lado da noção de "mudança social", é abordada nos capítulos 7 [O "significado social" e a explicação da acção social] e 8 [Princípios morais e mudança social]. Nesses capítulos, Skinner mostra sua dívida intelectual para com a sociologia compreensiva de Weber, ainda que destaque suas diferenças para com o pensador alemão. Sua discussão centra-se no embate entre as correntes naturalistas, que buscam explicações causais para as ações humanas (sociais) e as "antinaturalistas", estas derivadas das teorias de Dilthey, Weber e Wittgenstein, entre outros. Após expor os principais fundamentos dessas correntes e avaliá-las a partir de seu entendimento sobre os significados das ações sociais, Skinner resume sua posição da seguinte maneira:

Julgo não restarem dúvidas de que minha tese se posiciona num ponto intermédio [entre naturalistas e antinaturalistas], que creio ter sido ignorado, regra geral, nos debates filosóficos mais recentes sobre as explicações das acções. [...] Procurei argumentar, contudo, que embora possa haver explicações causais satisfatórias para as acções humanas voluntárias, podem também haver explicações satisfatórias para essas acções que não sejam nem causais, nem redutíveis a uma forma causal (p. 200 e 201).

Essa sua posição decorre do entendimento de que os "antinaturalistas" tendem a "aplicar o conceito de significado social de forma excessivamente lata" (p. 185), sem se preocuparem em compreender o que determinado agente social "estava a fazer" ao manifestar-se. A partir dessas considerações, Skinner procura reafirmar as implicações de sua metodologia, preocupada essencialmente em determinar as intenções do autor estudado, o qual, lembremo-nos, inscreve-se em um dado contexto intelectual.

No capítulo 9 [A ideia de um léxico cultural], Skinner realiza uma espécie de homenagem a Raymond Williams e desenvolve suas posições acerca de outro elemento essencial de seu método: as "palavras-chave que utilizamos para descrever e avaliar o mundo social” (p. 221). Williams é autor da obra intitulada Keywords: a vocabulary of culture and society, publicada em 1976 e reeditada em 1983, "em forma revista e aumentada" (no 
Brasil, o livro recebeu o título Palavras-chave: um vocabulário de cultura e sociedade, sendo publicado pela editora Boitempo, em 2007, a partir da edição inglesa de 1983). A discussão apresentada por Skinner orienta-se pela seguinte proposição: "se quisermos perceber como é que alguém vê o mundo - quais as distinções que estabelecem, quais as classificações que aceitam - o que precisamos de saber não é que palavras utilizam mas antes que conceitos possuem" (p. 222). Nesse caso, o termo conceito tem o mesmo sentido que o atribuído a "palavra-chave", ou seja, um termo que é empregado "para descrever e avaliar" o nosso meio social.

O objetivo de Skinner, neste capítulo 9, foi o de tentar "apresentar pelo menos um esboço daquilo que parece estar ausente no livro de Williams: uma abordagem do tipo de metodologia que seria necessário desenvolver de forma a utilizarmos o nosso vocabulário social como pontos de referência para uma maior compreensão do nosso mundo social”, inclusive de seus processos de mudança (p. 240). Embora o foco da argumentação esteja dirigido ao "nosso mundo social", entende-se que as palavras-chave são essenciais para a construção dos contextos sociais em que estão imersos os autores dos quais se está interpretando suas ideias por intermédio de seus textos. Nesse momento, é importante apontar a proximidade de Skinner com o método proposto por John Pocock, que se mostra interessado em

[...] decifrar a gramática mais profunda que se supõe estar nos textos estudados: seus termos básicos, as ocasiões típicas em que são empregados, o modo pelo qual se complementam e se opõem e assim por diante. [...] Assim, o intuito de desvendar as linguagens políticas [...] leva Pocock a investigar [...] não autores, mas termos-chave, cujo relacionamento recíproco, em complementaridade ou oposição, constituiria o cerne de uma determinada langue comum de autores - tanto aliados quanto adversários - que intervieram no período (ARAÚJO, 2003, p. 11).

O último capítulo do livro [Retrospectiva: estudar a retórica e a mudança conceptual] tem sua origem em um texto publicado em 1999, o mais recente da coletânea. Serve, por isso, para realizar um balanço das discussões antes apresentadas e, nesse sentido, Quentin Skinner destaca que 
[...] em muitos capítulos anteriores a minha atenção centrou-se na possibilidade de tratarmos o estudo da variação conceptual como uma prática distinta da investigação histórica. Como procurei sublinhar, se quisermos escrever esse tipo de história julgo imprescindível concentrarmo-nos, em particular, nos conceitos a que recorremos para descrever e analisar aquilo que Hobbes denominou como o nosso mundo artificial, ou seja, o mundo da política e da moralidade. O que significa, por sua vez, que o nosso estudo deve incidir sobre os vários termos todo o vocabulário normativo - em que esses conceitos são habitualmente reproduzidos (p. 245).

Esse capítulo também traz uma sucinta apresentação da trajetória intelectual de Skinner, apontando as principais discussões que manteve com filósofos e historiadores das ideias ingleses. Também deve ser destacado que, neste capítulo, há um breve comentário acerca das semelhanças e diferenças entre sua abordagem contextualista e a proposta de Koselleck "e dos seus discípulos, que sempre estiveram mais preocupados com a passagem lenta do tempo do que com o estudo pontilhista das mudanças conceptuais súbitas, como é o meu caso" (p. 252).

Enfim, para além de alguns percalços com o vocabulário empregado pelo tradutor português, Visões da política traz, para o interessado em conhecer melhor a abordagem de Skinner, um conjunto de indicações que, seguramente, o ajudarão a superar as dificuldades impostas por essa metodologia. Os dez capítulos contidos nessa obra também servem para reafirmar que "uma história das várias utilizações a que [as ideias] estiveram sujeitas por diferentes agentes em diferentes momentos do tempo [...] é a única história das ideias que pode ser escrita" (p. 247).

\section{Referências}

ARAÚJO, Cícero. Um "giro linguístico" na história das ideias políticas. In: POCOCK, John G. A. Linguagens do ideário político. São Paulo: Edusp, 2003, p. 9-21. 
JASMIN, Marcelo Gantus; FERES Jr., João. História dos conceitos: dois momentos de um encontro intelectual. In: JASMIN, M. G.; FERES Jr., João (Orgs.). História dos conceitos: debates e perspectivas. Rio de Janeiro: Editora PUC-Rio, 2006, p. 9-38.

LOPES, Marcos Antônio. Para ler os clássicos do pensamento político: um guia historiográfico. Rio de Janeiro: Editora FGV, 2002.

SKINNER, Quentin. As fundações do pensamento politico moderno. São Paulo: Companhia das Letras, 1996.

. La idea de libertad negativa: perspectivas filosóficas e históricas. In: RORTY, Richard; SCHNEEWINDT, J. B.; SKINNER, Q. (Comp.). La filosofia en la historia: ensayos de Historiografía de la Filosofia. Barcelona: Paidós, 1990, p. 227-259.

. Razão e retórica na filosofia de Hobbes. São Paulo: Editora da Unesp, 1999.

. Liberdade antes do liberalismo. São Paulo: Editora da Unesp, 1999.

. Visões da politica: sobre os métodos históricos. Algés: Difel, 2005.

TUCK, Richard. História do pensamento político. In: BURKE, Peter (Org.). A escrita da história: novas perspectivas. 4. reimpr. São Paulo: Editora da Unesp, 1992, p. 273-289.

Recebido em agosto de 2011. Aceito em agosto de 2011. 